\title{
EXPOSIÇÃO AO MEIO AMBIENTE DO TRABALHO PELA CONSTITUIÇÃO FEDERAL, EM CONECTIVIDADE À PROTEÇÃO LEGAL E PREVENÇÃO DOS RICOS, BASEADO NA DIGNIDADE DA PESSOA HUMANA.
}

\section{Marcela Garcia Cardoso e Silva ${ }^{1}$ Thais de Cunto Sarto ${ }^{2}$}

\section{RESUMO}

O trabalho objetiva estudar a exposição das pessoas ao meio ambiente do trabalho em consonância à Constituição Federal de 1988, abordando à proteção legal e a prevenção dos riscos, com base nos princípios da dignidade da pessoa humana, da prevenção e precaução. A metodologia utilizada é documental, jurisprudencial e bibliográfica. Em decorrência do acolhimento constitucional de entendimento amplo, tende-se a resguardar a saúde do trabalhador. A abordagem ocorrerá de forma minuciosa e detalhista, para o entendimento do contexto pesquisado e levando ao entendimento do tema.

Palavras-chave: direito do trabalho; meio ambiente; segurança; saúde; acidente;

\section{EXPOSURE TO THE ENVIRONMENT OF THE WORK BY THE FEDERAL CONSTITUTION, IN CONNECTIVITY TO THE LEGAL PROTECTION AND PREVENTION OF THE RICH, BASED ON THE DIGNITY OF THE HUMAN PERSON.}

\begin{abstract}
The objective of this study is to study the exposure of people to the work environment in line with the Federal Constitution of 1988, addressing legal protection and risk prevention, based on the principles of human dignity, prevention and precaution. The methodology used is documentary, jurisprudential and bibliographical. Due to the constitutional acceptance of a broad understanding, it tends to protect the health of the worker. The approach will take place in a detailed and thorough way, in order to understand the context and to understand the subject.
\end{abstract}

Keywords: labor law; environment; safety; health; accident;

\section{INTRODUÇÃO}

\footnotetext{
${ }^{1}$ Mestranda em Direito das Relações Sociais e Trabalhistas do Centro Universitário do Distrito Federal e Pósgraduada em Direito e Processo do Trabalho pelo IPOG. Endereço Postal: Rua 25-A, no 109, ap. 102, Setor Aeroporto, Goiânia/GO, CEP: 74070-150. E-mail: marcela_gcs@hotmail.com

${ }^{2}$ Mestranda em Direito das Relações Sociais e Trabalhista no Centro Universitário do Distrito Federal. Pósgraduada em Direito do Trabalho e Civil, Processo do Trabalho e Civil pela Universidade Cândido Mendes. Endereço Postal: Rua 227, Quadra 67, Lote 15/16, Residencial Cult World, ap. 608, Setor Leste Universitário, Goiânia/GO, CEP: 74.605-080. E-mail: thais.sarto@hotmail.com
} 
Não obstante o considerável avanço jurídico abarcado no âmbito ambiental, sobretudo na ordem constitucional, remanesce acentuado nível de limitação nos significados dos domínios jusambientais.

Segundo a Organização Internacional do Trabalho - OIT o Brasil é o $4^{\circ}$ país no mundo com o maior número de morte por acidentes de trabalho e, em que pese o empenho das autoridades competentes e de numerosas iniciativas para a diminuição desse índice, a quantidade de acidentes no local de trabalho cresce anualmente de modo preocupante. Um dos motivos que impossibilitam a atenuação dos incidentes é a escassez de investimentos em fiscalização, prevenção e conscientização, dos trabalhadores e dos empregadores sobre os meios efetivos e eficazes de segurança do meio ambiente do trabalho.

A Constituição Federal de 1988 tornou-se de suma importância na proteção dos interesses dos trabalhadores, especialmente na defesa do direito fundamental a um meio ambiente do trabalho salubre, destacando-se como instrumento indispensável ao enfrentamento das tragédias e outras ilegalidades.

Ela consagrou no art. $7^{\circ}$, XXII, o direito fundamental à redução dos riscos inerentes ao trabalho por meio de normas de saúde, higiene e segurança. Assegurou ainda no art. 225 o direito ao meio ambiente ecologicamente equilibrado, adicionando o meio ambiente do trabalho no art. 200, VIII, como o objetivo de assegurar os direitos fundamentais ao trabalho e à saúde elencados nos artigos $6^{\circ}$ e 196.

O presente trabalho tem por objetivo fazer algumas considerações sobre o meio ambiente de trabalho seguro e adequado sob a ótica do princípio constitucional da dignidade da pessoa humana e da proteção legal do meio ambiente do trabalho sob os princípios da prevenção e da precaução, na busca da adaptação do meio ambiente do trabalho para a manutenção da vida e da saúde dos trabalhadores.

Não ambicionamos, com esse breve trabalho, exaurir o tema, mas investigar e reflexionar sobre os princípios da prevenção e da precaução que são a base de um meio ambiente do trabalho protegido e adequado, aliado ao princípio da dignidade da pessoa humana, que garante aos trabalhadores ter seus direitos respeitados, tendo em vista sua relevante e primordial função na busca de materialidade dos direitos fundamentais. 


\section{EXPOSIÇÃO AO MEIO AMBIENTE DO TRABALHO PELA CONSTITUIÇÃO FEDERAL, EM \\ CONECTIVIDADE À PROTEÇÃO LEGAL E PREVENÇÃO DOS RICOS, \\ BASEADO NA DIGNIDADE DA PESSOA HUMANA}

Nesse contexto, precisamos refletir sobre os meios para solucionar a problemática existente no meio ambiente do trabalho, sempre tendo em mente que é importantíssimo buscar mecanismos para a melhoria das condições de trabalho dos trabalhadores e, acima de tudo, evitar acidentes cujos danos possam ser de difícil reparação ou irreparáveis.

Da perspectiva metodológica, o trabalho é uma pesquisa teórica que, desenvolvido com base na doutrina de renomados juristas, pretende analisar regramentos relativos ao meio ambiente de trabalho. É o que passamos a fazer nas linhas que se seguem.

\section{MEIO AMBIENTE DO TRABALHO, AS NORMAS CONSTITUCIONAIS E OS DIREITOS FUNDAMENTAIS}

De acordo com a Lei de Política Nacional do Meio Ambiente (artigo $3^{\circ}$, inciso I da Lei n. 6.938/81), meio ambiente é o conjunto de condições, leis, influências e interações de ordem física, química e biológica, que permite, abriga e rege a vida em todas as suas formas.

Este conceito é abrangente, no qual constata-se que o legislador inclinou-se para uma definição aberta, objetivando iniciar uma lacuna aplicada à normal legal, sendo esta em conformidade ao caput, do artigo 225 da Constituição Federal de 1988, pois procurou-se proteger as particularidades do meio ambiente (natural, artificial, cultural e do trabalho):

\footnotetext{
"Art. 225. Todos têm direito ao meio ambiente ecologicamente equilibrado, bem de uso comum do povo e essencial à sadia qualidade de vida, impondo-se ao Poder Público e à coletividade o dever de defendê-lo e preservá-lo para as presentes e futuras gerações."
}

As circunstâncias laborais às quais os trabalhadores são subjugados agem sobre a sua saúde e qualidade de vida. À vista disso é absolutamente preciso um sistema normativoconstitucional que the asseguram direitos e proteções. A Constituição abarcou no meio ambiente à classe de direito fundamental de terceira geração, isto é criado para o cuidado não apenas do homem separadamente, mas da coletividades, defendendo-o de imediato ao garantir a todos (JUNIOR e ARAUJO, 2018).

A Constituição destinou todo um capítulo ao meio ambiente (VI), elencando os aspectos fundamentais da "ordem social", que, segundo o Texto Magno, tem como 
sustentação a prioridade do trabalho, e como intuito o bem-estar e a justiça sociais. Compreende-se, assim, que, consoante a disposição hierárquica do sistema normativo jurídico constitucional, a mantença da ordem social com base nas características ora mencionadas é de extrema importância, pois é necessário que todos esses fatores encontrem-se apropriados em gozo e relacionados na sua execução, e dentre as propensões claramente sociais, como a educação, a cultura, os direitos das minorias, a ciência e a tecnologia, a Constituição listou também o meio ambiente (PADILHA, 2013).

Pode-se considerar também amplo englobando o meio ambiente (águas, solo, fauna, flora), o meio ambiente artificial (espaço urbano construído pelo homem), o meio ambiente cultural (sítios de valor histórico, artístico, arqueológico e científico), e o meio ambiente do trabalho (local de desenvolvimento das atividades laborais) (JUNIOR e ARAUJO, 2018).

Neste sentido, escreve Hugo Nigro Mazzilli (2012, p.161):

O conceito legal e doutrinário é tão amplo que nos autoriza a considerar de forma praticamente ilimitada a possibilidade de defesa da flora, da fauna, das águas, do solo, do subsolo, do ar, ou seja, de todas as formas de vida e de todos os recursos naturais, com base na conjugação do art. 225 da Constituição com as Leis n. 6.938/81 e 7.347/85. Estão assim alcançadas todas as formas de vista, não só aquelas da biota (conjunto de todos os seres vivos de uma região) como da biodiversidade (conjunto de todas as espécies de seres vivos existentes na biosfera, ou seja, todas as formas de vida em geral do planeta), e até mesmo está protegido o meio que as abriga ou lhes permite a subsistência.

Os princípios, conjuntos de orientações (normas, regras, etc) e propósitos singulares conduzem o meio ambiente, como verifica-se na Política Nacional do Meio Ambiente, o qual sua maior finalidade é cuidar e proteger a vida de todas as espécies e, principalmente, a vida humana, esta primordial (MELO, 2013).

A proteção estatuída no artigo 225 da Constituição Federal denota indiscutível ligação com os métodos e procedimentos concernentes à justiça, igualdade, da elevação do 


\section{EXPOSIÇÃO AO MEIO AMBIENTE DO TRABALHO PELA CONSTITUIÇÃO FEDERAL, EM \\ CONECTIVIDADE À PROTEÇÃO LEGAL E PREVENÇÃO DOS RICOS, \\ BASEADO NA DIGNIDADE DA PESSOA HUMANA}

desenvolvimento nacional e do bem-estar de todos, em concordância com o artigo $3^{\text {o; }}$ ao direito à vida, função social da propriedade e a ação popular, consoante o caput do artigo $5^{\circ} \mathrm{e}$ seus incisos XXIII e LXXIII, todos da Constituição (JUNIOR e ARAUJO, 2018).

O $1^{\circ}$ princípio da Declaração do Rio sobre Meio Ambiente e Desenvolvimento expõe que "Os seres humanos estão no centro das preocupações com o desenvolvimento sustentável. Têm direito a uma vida saudável e produtiva, em harmonia com a natureza". Se vê portanto que o direito ao meio ambiente harmonioso, objetivamente, está inserido no rol dos Direitos Humanos (FILHO E FERREIRA, 2018).

Cuidar e proteger um ambiente de trabalho livre de perigo, que proporcione condições favoráveis físicas ou psíquicas para uma boa execução das atividades laborativas, o qual a todo o tempo é uma inquietação ao mundo. Evidencia-se isto com a aplicação das normas internacionais, a exemplo de Convenções da OIT, instruções normativas, a Consolidação das Leis Trabalhistas (CLT) e a Constituição Da República Federativa do Brasil (FILHO E FERREIRA, 2018).

A novidade descrita no artigo 611-A da Lei 13.467/2017, especificadamente nos incisos XII e XIII, autorizou que convenção coletiva e o acordo coletivo de trabalho definam o grau de insalubridade do ambiente laboral, ademais de consentir a prorrogação de jornada nestes ambientes, dispensando a concordância da autoridade competente do Ministério Público, e o que é, claramente, uma exceção ao artigo 611-B, incisos XVII e XVIII, igualmente agregados à CLT (FILHO E FERREIRA, 2018). Importante mencionar neste ponto é a nova visão da primazia do negociado sobre o legislado em um assunto onde a ordem pública predomina por estar totalmente ligado à vida e à saúde humana (FILHO E FERREIRA, 2018).

Com os sindicatos fragilizados e marginalizados, acredita-se em uma "imposição" pela parte empresarial no intuito de beneficiá-la no mercado. Porém a autonomia da vontade individual do trabalhador está muito presente na nova lei, como por exemplo, art. $4^{\circ}, \S 2^{\circ}$ da CLT, arts. 59, 59-A e 59-B, art. 75-C, $\S 1^{\circ}$, art. 75-D, art. 134, $\S 1^{\circ}$, art. 394-A, art. 442-B, art. 452-A, $\S 4^{\circ}$, art. 507-B, entre outros (LOPES e ROCHA, 2017). 
Por conseguinte, a Lei $13.467 / 17$ alterou numerosos dispositivos legais que repercutiram no meio ambiente do trabalho, fragilizando a qualidade de vida do trabalhador e permitindo, de uma forma mais vulnerável que já é, o seu adoecimento adiantado, possibilitando até mesmo um final triste com o óbito, consequentes de acidentes de trabalho (FILHO E FERREIRA, 2018).

Afirma Professor Ricardo José Macêdo de Britto Pereira (2017, p. 429):

Concentrar nas mãos do empresário isoladamente ou em conjunto com o sindicato profissional a gestão do tempo de trabalho, vista pela perspectivamente puramente administrativa ou econômica, pode sugerir maior racionalidade da produção. Esse ponto, porém, não pode figurar como objeto isolado de análise. Do lado dos prestadores de serviços, é necessário preservar a sua saúde e segurança e a flexibilização da duração do trabalho representa riscos neste aspecto.

Todos, inclusive os trabalhadores, têm direito a uma vida minimamente boa, a exercer sua liberdade, a ter dignidade respeitada. Logo não é difícil perceber que essa é uma característica objetiva da relação social que se estabelece entre trabalho e capital. A critica que se faz é ainda interligada os preceitos constitucionais nesta descrita, porque se os brasileiros fossem ficar a mercê da Lei 13.467/17 pioraria cada vez mais a situação na prática, pois, em alguns aspectos, absolutamente nada contribuiu para a modernização (SEVERO, 2017).

\section{3. À PROTEÇÃO LEGAL E O PRINCÍPIO DA DIGNIDADE DA PESSOA HUMANA}

Para o legislador constitucional a maior conexão do meio ambiente do trabalho é a saúde pública, contudo, não se pode esquecer que o conceito contemporâneo de saúde, de acordo com a Organização Mundial da Saúde (OMS), é o de que "a saúde é um estado de completo bem-estar físico, mental e social, e não somente a ausência de doença ou enfermidade" (PADILHA, 177, 2013 apud Comissão Nacional da Reforma Sanitária, Relatório final da $8^{\text {a }}$ Conferência Nacional de Saúde, 1986).

Neste sentido frisa o Professor Raimundo Simão (2013, p.136): 


\section{EXPOSIÇÃO AO MEIO AMBIENTE DO TRABALHO PELA CONSTITUIÇÃO FEDERAL, EM \\ CONECTIVIDADE À PROTEÇÃO LEGAL E PREVENÇÃO DOS RICOS, \\ BASEADO NA DIGNIDADE DA PESSOA HUMANA}

Não obstante a existência de todo esse arcabouço jurídico protetivo, é muito preocupante a situação brasileira em termos de proteção ambiental no trabalho e de defesa da saúde dos trabalhadores, haja vista os altos índices de acidentes de trabalho registrados pela Previdência Social, com grandes prejuízos para a economia brasileira e para a sociedade. São mais de 700 mil acidentes de trabalho por ano, mais de 80 mil trabalhadores mutilados, mais de 2.500 mortes. No Estado de São Paulo, por exemplo, ocorre uma morte a cada 1,5 hora. Os acidentes de trabalho matam mais do que a AIDS e, no mundo, mais do que as guerras, o trânsito e a violência. O custo para o Estado Brasileiro equivale a cerca de $5 \%$ do PIB, além dos gastos das empresas e dos altos custos sociais e humanos decorrentes. Quer dizer, estamos diante de uma calamidade pública e muitos não viram ou não querem ver. As causas principais são o descumprimento das normas de saúde, higiene e segurança no trabalho, a precarização das condições de trabalho, agravada pelas terceirizações, nas quais ocorrem a maioria dos acidentes e pela ineficiência da fiscalização estatal.

Necessário lembrar que em 2014 o Tribunal Superior do Trabalho, com a ajuda do Conselho Superior da Justiça do Trabalho (CSJT), e com o apoio dos 24 Tribunais Regionais do Trabalho, além das parceiras do Programa Trabalho Seguro, lançaram campanha de prevenção de acidentes com o objetivo chamar a atenção da sociedade para a importância de ações de prevenção.

Neste sentido expõe claramente Norma Sueli Padilha (2013, p. 178):

$\mathrm{O}$ direito humano fundamental do trabalhador ao meio ambiente do trabalho equilibrado irradia seus efeitos no contrato do trabalho, e como norma de ordem pública, impõe ao empregador o compromisso com a sadia qualidade de vida de todos os trabalhadores no ambiente laboral, e com a sua proteção contra os riscos inerentes à atividade econômica, cabendo-lhe atuar por meio de práticas sustentáveis e de 
equidade, priorizando práticas de precaução e a promoção do desenvolvimento sustentável em prol dos seus funcionários e da comunidade.

A conexão direta da proteção da saúde e qualidade de vida do trabalhador a estabilidade do meio ambiente é fruto da titulação do próprio meio ambiente do trabalho na qualidade de direito fundamental, e impõe ao interpretador e legislador uma nova e importante conduta, direcionada à melhoria neste enfoque de execução da proteção do trabalhador no seu ambiente laboral, em uma concepção extensa, mais ampla e jungida. (PADILHA, 2013, p. 177)

Por esse ângulo, a aplicação dos princípios do direito ambiental clama por uma fundamental reorganização e reexame dos métodos de concretização da atividade econômica e a maneiros como o trabalhador se introduz no referido processo, na procura de sua proteção em desfavor de qualquer destruição e poluição do meio ambiente no local de labor. (PADILHA, 2013, p. 180)

A execução dos princípios ambientais é de grande proveito no alargamento das esferas de proteção jurídica do trabalhador no seu ambiente de trabalho, pois é a linha que instrui todo o direito ambiental em harmonia com a prevenção. (PADILHA, 2013, p. 180)

\subsection{PROTEÇÃO LEGAL DO MEIO AMBIENTE DO TRABALHO: OS PRINCÍPIOS DA PREVENÇÃO E DA PRECAUÇÃO}

O meio ambiente do trabalho, em conformidade com o conceito de meio ambiente, encontra-se incorporado no meio ambiente artificial. É o espaço em que o empregado exerce seu labor e onde vive a maior parte da vida.

O dano ambiental, quando ocorre, pode ser de difícil reparação ou irreparável. Nessa conjuntura o ordenamento jurídico brasileiro utiliza, como proteção legal, os princípios da prevenção e da precaução, sendo estes indispensáveis à proteção do meio ambiente, pois têm o escopo de evitar que o dano ocorra. 


\section{EXPOSIÇÃO AO MEIO AMBIENTE DO TRABALHO PELA CONSTITUIÇÃO FEDERAL, EM \\ CONECTIVIDADE À PROTEÇÃO LEGAL E PREVENÇÃO DOS RICOS, \\ BASEADO NA DIGNIDADE DA PESSOA HUMANA}

Indispensável, também, é diferenciar tais princípios, compreendendo que a prevenção diz respeito aos danos previsíveis, e a precaução aos danos sobre os quais ainda não há evidência, cujo risco ainda é imprevisto.

Milaré (2005, p. 165), comenta "que há juristas que se referem ao princípio da prevenção, enquanto outros reportam-se ao princípio da precaução. Há, também, os que usam ambas as expressões, supondo ou não diferença entre elas”. Em que pese, à primeira vista, aparentarem, ter o mesmo significado, são princípios diferentes, mesmo que, sutilmente, possuam correlação entre si, um é gênero e o outro, espécie. Sirvinskas (2008, p. 57), destaca:

[...] entendemos que a prevenção é gênero das espécies precaução e cautela, ou seja, é agir antecipadamente. Prevenção, como se pode notar, tem o significado de antecipar o fato. Já cautela significa a atitude ou cuidado que se deve ter para evitar danos ao meio ambiente ou a terceiros. O conceito de prevenção é mais amplo do que precaução ou cautela.

O princípio da prevenção é tido como aquele que determina adoção das medidas preventivas aos danos ambientais suscetíveis de impactos futuros. Antunes (2008, p.45), define como:

O princípio da prevenção aplica-se a impactos ambientais já conhecidos e dos quais se possa, com segurança, estabelecer um conjunto de nexos de causalidade que seja suficiente para identificação de impactos futuros. Com base no princípio da prevenção, o licenciamento ambiental e, atém mesmo, os estudos de impacto ambiental podem ser realizados e são solicitados pelas autoridades públicas. (..) O licenciamento ambiental, na qualidade de principal instrumento apto a prevenir danos ambientais, age de forma a evitar e, especialmente, minimizar e mitigar os danos que uma determinada atividade causaria ao meio ambiente, caso não fosse submetida ao licenciamento ambiental. 
Belchior (2011, p. 208-209) explica que o princípio da prevenção está contido nos incisos II, III, IV, e V do $\S 1^{\circ}$ do art. 225 da Constituição Federal de 1988. Fundamenta-se na antecipação de medidas que possam evitar a ocorrência de um dano provável, em um determinado acontecimento, minimizando ou excluindo suas causas, quando se sabe do risco concreto.

Já o princípio da precaução consiste na adoção antecipada de medidas amplas, eficazes e economicamente viáveis de prevenção da degradação do meio ambiente nas circunstâncias cujas ações podem implicar graves danos, ou danos ambientais irreversíveis. Milaré (2005, p. 167) afirma que "a incerteza científica milita em favor do meio ambiente, carregando-se ao interessado o ônus de provar que as intervenções pretendidas não trarão consequências indesejadas para o meio ambiente”. Rodrigues (2002, p. 150), por sua vez, enfatiza que "tem-se utilizado o postulado da precaução quando pretende-se evitar risco mínimo ao meio ambiente, nos casos de incerteza científica acerca de sua degradação".

Derani (2008, p. 149-152) enfatiza que a execução do princípio da precaução objetiva "garantir uma suficiente margem de segurança da linha do perigo" e, por isso, precede a sua manifestação. É uma conduta de cautela, cujo intuito é prevenir para evitar um possível risco, ainda que indeterminado, tentando reduzir o "potencial danoso oriundo do conjunto de atividade". Precaução é prudência, in dubio pro securitate, que assim ergueu-se como linha mestra do direito ambiental, sendo sua aplicação e execução de suma importância, inclusive no meio ambiente do trabalho, especialmente após a promulgação do Código Civil de 2002, que no art. 927, parágrafo único, acolheu a teoria do risco na fixação da responsabilidade objetiva.

É inegável que tais princípios são normas fundamentais do direito ambiental e determinam o dever de priorizar medidas de proteção integral ao meio ambiente diante da impossibilidade da total reparação em caso de acidentes. Milaré (2005, p. 166), ao falar sobre o direito ambiental afirma que "sua atenção está voltada para momento anterior ao da consumação do dano - o do mero risco. Ou seja, diante da pouca valia da simples reparação, sempre incerta e, quando possível, excessivamente onerosa, a prevenção é a melhor, quando não a única, solução." 


\section{EXPOSIÇÃO AO MEIO AMBIENTE DO TRABALHO PELA CONSTITUIÇÃO FEDERAL, EM \\ CONECTIVIDADE À PROTEÇÃO LEGAL E PREVENÇÃO DOS RICOS, \\ BASEADO NA DIGNIDADE DA PESSOA HUMANA}

A Convenção $\mathrm{n}^{\circ} 155$ da OIT, que versa sobre a segurança e saúde dos trabalhadores e o meio ambiente de trabalho, foi ratificada pelo Brasil (Decreto-Legislativo $\mathrm{n}^{\circ}$ 2/92 e Decreto $\mathrm{n}^{\mathrm{o}}$ 1.254/94). Em seu art. $3^{\circ}$, alínea $e$, está definido que “o termo saúde, com relação ao trabalho, abrange não só a ausência de afecções ou de doenças, mas também os elementos físicos e mentais que afetam a saúde e estão diretamente relacionados com a segurança e a higiene no trabalho."

Ainda em seu art. $4^{\circ}$, item 2 , decreta que a política estatal tem como objetivo “(...) prevenir os acidentes e os danos à saúde que forem consequência do trabalho, tenham relação com a atividade de trabalho, ou se apresentem durante o trabalho, reduzindo ao mínimo, na medida em que for razoável e possível, as causas dos riscos inerentes ao meio ambiente de trabalho.”

A convenção $\mathrm{n}^{\circ} 161$ da OIT, também recepcionada pelo Brasil (Decreto-Legislativo $n^{\circ} 86 / 89$ e Decreto $n^{\circ} 127 / 91$ ), que versa sobre serviços de saúde do trabalho, segue nesse mesmo fundamento, ao dar prioridade em seu art. $1^{\circ}$, I e II, as funções essencialmente preventivas dos serviços de saúde no trabalho, que devem aconselhar o empregador, os trabalhadores e seus representantes na empresa sobre ao:

I - requisitos necessários para estabelecer e manter um ambiente de trabalho seguro e salubre, de molde a favorecer uma saúde física e mental ótima em relação com o trabalho;

II - a adaptação do trabalho às capacidades dos trabalhadores, levando em conta seu estado de sanidade física e mental.

Nesse contexto torna-se de suma importância proceder à leitura constitucional dos preceitos, como afirma Silva (2007, p. 22), de maneira que tais princípios possuem farto campo de aplicação no meio ambiente de trabalho. O contratante que não garante um local de trabalho salubre, em condições equilibradas de saúde e segurança infringe, também, o princípio da boa-fé objetiva e não atende à função social do contrato de trabalho.

Diniz (2009, p. 236) esclarece que, "o meio ambiente, inclusive o do trabalho, é correlacionado diretamente na Constituição Federal ao bem objeto de direito sobre o qual incide o interesse da coletividade: a saúde humana" e toda a legislação constitucional, 
infraconstitucional, associadas "às convenções internacionais, ratificadas no Brasil, procuram dar substrato para que o ambiente de trabalho apresente cada vez menos riscos e gere, por consequência, cada vez menos danos" (DINIZ, 2009, p. 237).

Desde o julgamento do RE 466.343-SP, o STF vem decidindo de acordo com o assentado no $\S 2^{\circ}$ do art. $5^{\circ}$ da Constituição Federal de 1988, os preceitos internacionais validados pelo Brasil entram no ordenamento jurídico nacional como norma supralegal.

Assim a menção à "lesão ou ameaça de direito", descrita no inciso XXXV do art. $5^{\circ}$ da Constituição Federal de 1988, referente ao meio ambiente de trabalho, deve ser analisada sob a ótica de se evitar a ocorrência da lesão, baseando-se nos princípios da precaução e da prevenção e não apenas de forma limitada, fundamentando-se apenas como resposta a ameaça concreta ou lesão já perpetrada. Nesse sentido, Padilha (2002, p. 32) ressalta:

(...) quando a Constituição Federal, em seu art. 225, fala em meio ambiente equilibrado, está mencionando todos os aspectos do meio ambiente. E, ao dispor, ainda, que o homem para encontrar uma sadia qualidade de vida necessita viver neste ambiente ecologicamente equilibrado, tornou obrigatória também a proteção do ambiente no qual o homem, normalmente, passa a maior parte de sua vida produtiva, qual seja, o do trabalho.

A Constituição Federal, ao discorrer especialmente da saúde, deixa evidente o caráter preventivo das políticas públicas a ela relacionadas, entretanto, não só àquelas diretamente relacionadas, mas também àquelas que se relacionam de maneira transversa:

Art. 196. A saúde é direito de todos e dever do Estado, garantido mediante políticas sociais e econômicas que visem à redução do risco de doença e de outros agravos e ao acesso universal e igualitário às ações e serviços para sua promoção, proteção e recuperação.(...)

Art. 198. As ações e serviços públicos de saúde integram uma rede regionalizada e hierarquizada e constituem um sistema único, organizado de acordo com as seguintes diretrizes:(...) 


\section{EXPOSIÇÃO AO MEIO AMBIENTE DO TRABALHO PELA CONSTITUIÇÃO FEDERAL, EM \\ CONECTIVIDADE À PROTEÇÃO LEGAL E PREVENÇÃO DOS RICOS, \\ BASEADO NA DIGNIDADE DA PESSOA HUMANA}

II - atendimento integral, com prioridade para as atividades preventivas, sem prejuízo dos serviços assistenciais.

A Consolidação das Leis do Trabalho, em seu capítulo V, versa sobre as normas de segurança e a medicina do trabalho. De modo geral o capítulo se dedica a estipular a necessidade de cumprimento, dos empregados e empregadores, a todas as normas legais e infralegais que protejam a segurança do trabalhador assim como da incumbência do Estado de regular, coordenar e fiscalizar a execução da normatização.

Esse capítulo possui dispositivos que versam sobre medidas protetivas à prevenção de acidentes ou de doenças físicas e/ou mentais associadas ao ambiente de trabalho, como exemplo a efetuação de exames admissionais, periódicos e demissionais; do regulamento da estrutura física onde será realizado o trabalho; da entrega de equipamentos de proteção individual; dos critérios de iluminação e conforto térmico para os funcionários, entre tantos outros.

A Portaria $n^{\circ} 3.214 / 78$ aprovou Normas Regulamentadoras, altamente preventivas, que detalham as normas trazidas pela Consolidação das Leis do Trabalho, sendo a NR ${ }^{\circ} 02$ a que mais se destaca. Ela traz em seu texto a determinação de inspeções antecipadas nas empresas, ou seja, antes do início de suas atividades, e se necessário, essas instalações deverão ser submetidas a modificações para assegurar a segurança do meio ambiente do trabalho, tentando assim evitar acidentes. Como bem destaca Diniz (2009, p. 240), "não deixa a inspeção, guardadas as especificidades de cada um, de possuir certa semelhança com o estudo prévio de impacto ambiental".

A Constituição Federal determina que seja feito o Estudo Prévio de Impacto Ambiental para que possam ser realizados empreendimentos e projetos efetivamente poluidores ou até hipoteticamente poluidores, apesar disso Antunes (2008, p. 277) aduz que “a experiência jurídica brasileira, no entanto, demonstra que a norma constitucional tem suscitado muitas dúvidas e divergências no que se refere a sua adequada compreensão"

Desse modo é complexo afirmar terminantemente que se trata de instituto preventivo e de precaução que defende com eficiência prática o meio ambiente do trabalho, tendo em vista as peculiaridades dessa aparência de meio ambiente e o fato de ter sido o Estudo Prévio 
de Impacto Ambiental um instituto criado especialmente para o meio ambiente em seu aspecto natural.

A Política Nacional de Meio Ambiente, estabelecida pela Lei no 6938/81, definiu como um dos mecanismos de gestão ambiental as atuações preventivas que devem ser executadas pelo Estado, entre elas o estudo de impactos ambientais para a instalação de obras ou atividades potencialmente poluidoras.

Milaré (2005, p. 482) ressalta que a avaliação de impacto ambiental "pode ser implementada tanto para projetos que envolvam execução física de obras e processos de transformação como para políticas e planos que contemplem diretrizes programáticas, limitadas ao campo das ideias, neste caso denominada Avaliação Ambiental Estratégica”.

$\mathrm{O}$ art. $1^{\circ}$, III, da Resolução CONAMA 237/97, traz a Avaliação de Impacto Ambiental, por ela intitulada de "Estudos Ambientais", é gênero do qual são espécies todos os estudos para análise da licença ambiental, tais como: relatório ambiental, plano e projeto de controle ambiental, relatório ambiental preliminar, diagnóstico ambiental, plano de manejo, plano de recuperação de área degradada e análise preliminar de risco. Outras espécies de Estudos Ambientais podem ser solicitadas nos casos em que não se exigem o Estudo de Impacto Ambiental.

Nessa conjuntura, a inspeção prévia prevista na NR $n^{\circ} 02$ pode ser classificada como um meio de mensurar os impactos sobre o ambiente do trabalho, operando como instrumento de prevenção e também de precaução, já que ela pode apontar cenários em que não se tenha certeza sobre os possíveis danos previsíveis ou aqueles cujo risco ainda é imprevisto, determinando assim a execução de medidas mitigatórias.

Compreende-se, assim, que a legislação do meio ambiente do trabalho no ordenamento jurídico brasileiro acolheu, por completo, os princípios ambientais da prevenção e da precaução.

Para Diniz (2009, p. 248) tem-se que "a abordagem preventiva é mais adequada à defesa do ambiente, na medida em que o dano ambiental implica sempre um custo social elevado e deve, sempre que possível, ser evitado", aplicando-se também, na íntegra, ao meio ambiente do trabalho. 


\section{EXPOSIÇÃO AO MEIO AMBIENTE DO TRABALHO PELA CONSTITUIÇÃO FEDERAL, EM \\ CONECTIVIDADE À PROTEÇÃO LEGAL E PREVENÇÃO DOS RICOS, \\ BASEADO NA DIGNIDADE DA PESSOA HUMANA}

É relevante frisar a premência de regramento normativo específico para proteger cada um dos elementos do meio ambiente, uma vez que cada um deles carrega características próprias, que, inúmeras vezes, tornam ineficazes alguns institutos preventivos e de precaução que se prestam satisfatoriamente a proteger inúmeros outros aspectos. Sob essa perspectiva afirma-se a premência de ponderar e tentar, o melhor possível, esmiuçar a legislação de proteção de cada um dos elementos do meio ambiente em conformidade, específica, com os princípios instrumentais da prevenção e da precaução.

\section{CONCLUSÃO}

A Lei n. 13.467/17, além de algumas alterações, promoveu grande flexibilização nas normas de duração do trabalho, consequentemente esvaziou a proteção estabelecida pelas normas de saúde, higiene e segurança no trabalho.

Nos âmbitos produtivos do Brasil os números de acidentes de trabalhos são altos e assustadores porque, levando em consideração as atividades perigosas e riscos exacerbados, inúmeros empregadores não estão aplicando as medidas de prevenção como devem ser seguidas as normas legais e o bom senso, ocasionando inumeráveis prejuízos e resultados com sequelas para as padecedores, para a coletividade e empresas.

O direito não se satisfaz, assim, em consertar e refrear o dano ambientar, porque uma vez ocorrida a degradação do ambiente, em regra, é insanável. Prevenir o incidente de danos ambientais é elemento essencial e indispensável do direito ambiental para conseguir alcançar o propósito fim, qual seja de proteção e melhoria das particularidades do meio ambiente.

Destaca-se que os princípios de prevenção de danos e da precaução são inseridos no cerne da principiologia do direito ambiental, já que é necessário que as medidas que evitem danos ao meio ambiente sejam priorizadas ou extinguem as causas de ameaça à qualidade ambiental. Os referidos princípios requerem que sejam adotadas pelas instituições, políticas criteriosas e prudentes de gestão ambiental, não somente para gestão de fontes de poluição ou degradação ambiental que já existem, mas também com práticas preservativas que materializam o princípio da precaução.

\section{BIBLIOGRAFIA}


ANTUNES, Paulo de Bessa. Direito Ambiental. 11. ed. Rio de Janeiro: Lumen Juris Editora, 2008.

BELCHIOR, Germana Parente Neiva. Hermenêutica Jurídica Ambiental. São Paulo: Saraiva, 2011.

BRASIL. CONAMA. Resolução $\mathbf{n}^{\circ}$ 237, de 19 de dezembro de 1997. In: <http:// www.mma.gov.br> Acesso em 15 de outubro de 2019.

BRASIL. Constituição da República Federativa do Brasil, de 05 de outubro de 1988. In:<http://www.planalto.gov.br> Acesso em 03 de março de 2019.

BRASIL. Decreto $\mathbf{n}^{0}$ 127, de 22 de maio de 1991. Convenção $n^{0} 161$ da OIT. In:<http://www.planalto.gov.br> Acesso em 01 de março de 2019.

BRASIL. Decreto $n^{0} \mathbf{1 . 2 5 4}$, de 29 de setembro de 1994. Convenção $n^{\circ} 155$ da OIT. In:<http://www.planalto.gov.br> Acesso em 01 de março de 2019.

BRASIL. Decreto no 5.098, de 03 de junho de 2004. In: <http:// www.mma.gov.br> Acesso em 15 de outubro de 2019.

BRASIL. Decreto-Legislativo $n^{0} 2$ de 17 de março de 1992. Convenção $n^{\circ} 155$ da OIT. In:<https://www2.camara.leg.br> Acesso em 01 de março de 2019.

BRASIL. Decreto-Legislativo no 86 de 14 de dezembro de 1989. Convenção no 161 da OIT. In:<https://www2.camara.leg.br> Acesso em 01 de março de 2019.

BRASIL. Instrução Normativa $\mathbf{n}^{0}$ 0001, de 17 de maio de 1983. Norma Regulamentadora $\mathrm{n}^{\circ}$ 02. In: <http://www.trt02.gov.br/geral/tribunal2/LEGIS/CLT/NRs/NR_2.html> Acesso em 03 de março de 2019.

BRASIL. Lei ${ }^{\circ}$ 6.938, de 31 de agosto de 1981. In:<http://www.planalto.gov.br > Acesso em 15 de outubro de 2019.

BRASIL. Portaria $\mathbf{n}^{\mathbf{0}}$ 3.214, de 08 de junho de 1978. In: <http://www.trtsp.jus.br/geral/tribunal2/ORGAOS/MTE/Portaria/P3214_78.html> Acesso em 03 de março de 2019.

BRASIL. Superior Tribunal Federal. RE 466.343-SP. In:<http://portal.stf.jus.br/> Acesso em 01 de março de 2019.

CSJT e TST lançam nova campanha de prevenção de acidentes. 2014. Disponível em:http://www.tst.jus.br/web/trabalhoseguro/programa/-/asset_publisher/0SUp/content/csjt-etst-lancam-nova-campanha-de-prevencao-de-acidentes?inheritRedirect=false. Acesso em: 03/04/2019 às 19:16.

DERANI, Cristiane. Direito Ambiental Econômico. 3. ed. São Paulo: Saraiva, 2008.

DINIZ, Bismarck Duarte. Apontamentos acerca do direito ambiental do trabalho. In: MAZZUOLI, Valerio de Oliveira; IRIGARAY, Carlos Teodoro José Hugueney (Orgs.). Novas perspectivas do direito ambiental brasileiro: visões interdisciplinares. Cuiabá: Cathedral, 2009. 
FILHO, José Claudio Monteiro de Brito; Ferreira, Vanessa Rocha. Seguridade social e meio ambiente do trabalho: direitos humanos nas relações sociais: tomo II, volume I /Coordenadores Cláudio Jannotti da Rocha ... [et al. ]. - Belo Horizonte: RM, 2018. p. 127.

JÚNIOR, Miguel Horvath; Araujo, Gustavo Berão. Seguridade social e meio ambiente do trabalho: direitos humanos nas relações sociais: tomo I, volume I /Coordenadores Cláudio Jannotti da Rocha ... [et al. ]. - Belo Horizonte: RTM, 2018, p. 326 e p. 329

MAZZILLI, Hugo Nigro. A defesa dos interesses difusos em juízo: meio ambiente, consumidor, patrimônio cultural, patrimônio público e outros interesses. 25 ed. São Paulo: Saraiva, 2012, p.161.

MELO, Raimundo Simão De. Artigos: Meio Ambiente do Trabalho e Atividades de Risco: Prevenção e Responsabilidades. Revista Eletrônica. Outubro de 2013. p. 132.

MILARÉ, Édis. Direito do Meio Ambiente. 4. ed. São Paulo: Editora Revista dos Tribunais, 2005.

PADILHA, Norma Sueli. Meio Ambiente Do Trabalho: Um Direito Fundamental do Trabalhador e a Superação da Monetização do Risco. Rev. TST, Brasília, vol. 79, nº 4, out/dez 2013, p. 176.

PADILHA, Norma Sueli. Do meio ambiente do trabalho equilibrado. São Paulo: LTr, 2002. p. 32.

PEREIRA, Ricardo José Macêdo de Britto. Saúde, higiene e segurança no trabalho no contexto do Trabalho digno: A fragmentação do meio ambiente de trabalho operada pela reforma trabalhista. MELO, Raimundo Simão de e ROCHA, Cláudio Jannotti da (Coord.). Constitucionalismo, trabalho, seguridade social e as reformas trabalhistas e providenciaria. São Paulo: LTr, 2017

RODRIGUES, Marcelo Abelha. Instituições de Direito Ambiental. Vol. 1. São Paulo: Max Limonad, 2002.

LOPES, Marcus Aurélio; ROCHA, Valéria Rodrigues Franco da. Algumas das Mudanças que a Lei 13.467/17 repercutem nas Normas de Segurança e Medicina do Trabalho e na Autonomia de Vontades do Meio Ambiente de Trabalho. Revista Eletrônica Segurança e Saúde no Trabalho. Tribunal Regional do Trabalho da 9a Região. V.7 - n. 64. Ano VII 2017. p. 10

SEVERO, Valdete Souto. O ideal de construção de um ambiente de trabalho saudável e os desafios da Lei n. 13.467/17: Elementos para resistência. MELO, Raimundo Simão de e ROCHA, Cláudio Jannotti da (Coord.). Constitucionalismo, trabalho, seguridade social e as reformas trabalhistas e providenciaria. São Paulo: LTr, 2017.

SILVA, José Afonso da. Direito Ambiental Constitucional. 6. ed. São Paulo: Malheiros, 2007.

SIRVINSKAS, Luís Paulo. Manual de Direito Ambiental. 6. ed. São Paulo: Editora Saraiva, 2008 . 